\title{
ANALISIS KEAUSAN DAN WAKTU PENGEREMAN KAMPAS CAKRAM ASBESTOS DAN NON ASBESTOS DENGAN VARIASI BEBAN PENGEREMAN DAN BERAT PENGENDARA PADA SEPEDA MOTOR HONDA SUPRA X 125 CC
}

\author{
Sayid Khaidir Ali Mulahela ${ }^{1 *}$, Agus Dwi Catur ${ }^{2}$, Pandri Pandiatmi ${ }^{3}$ \\ ,2,3 Jurusan Teknik Mesin, Fakultas Teknik Universitas Mataram \\ JI. Majapahit No. 62 Mataram NTB Telp. (0370)636126 ext.128, (0370)636087 \\ *Email : haidirmulahela@yahoo.com
}

\begin{abstract}
Brake system is an important thing of vehicle. Many kinds of brake pads presents by each factory. Brake pads made of asbestos and non asbestos material. Each of them have excess and lack. This research aims to know the performance of each type of brake pads so that it can show the excess and lack of each type of product. As user, we have to choose a product which will be used in our vehicle cleverly.

The research be done by giving variations in load of brake and weight of rider at a constant speed. The load of brake used spring with the variation are $2 \mathrm{~kg}, 3 \mathrm{~kg}$ and $4 \mathrm{~kg}$. While, weight rider are varied with $54 \mathrm{~kg}$ and $111 \mathrm{~kg}$.

Research result shows that increasing load of pull brake led to increasing the value of worn out and a decline in the braking time, while increasing weight of the rider causes an increase in the value of worn out and braking time at all types of brake pad products. In dry condition, the lowest wear is $1,37 \times 10^{-4} \mathrm{~mm} / \mathrm{second}$ in non asbestos pads and the highest wear is $3,088 \times 10^{-5} \mathrm{~mm} / \mathrm{second}$ in asbestos pads. While, the smallest braking time is 28,79 seconds in asbestos pads and the biggest is 64,26 seconds in non asbestos pads. In wet condition, the lowest wear is $2,422 \times 10^{-5} \mathrm{~mm} / \mathrm{second}$ in asbestos pads and the highest wear is $7,716 \times 10^{-5}$ $\mathrm{mm} / \mathrm{second}$ in non asbestos pads. While, the smallest braking time is 29,46 seconds in non asbestos pads and the biggest is 62,71 seconds in asbestos pads.
\end{abstract}

Key word: Brake pad, wear, time, load, weight

\section{LATAR BELAKANG}

Sistem pengereman adalah suatu perangkat yang sangat penting dalam suatu kendaraan. Pengereman berfungsi untuk memperlambat dan menghentikan laju suatu kendaraan. Berbagai jenis dan merek kampas cakram yang ditawarkan oleh berbagai produsen. Kita sebagai konsumen harus cerdas dalam memilih jenis kampas cakram yang akan kita gunakan. Jika kita tidak cerdas dalam memilih jenis kampas cakram yang aman dan ramah lingkungan, maka nyawalah taruhannya.

Kampas cakram sepeda motor ada yang terbuat dari bahan asbes dan ada yang terbuat dari bahan non asbes. Keduanya memilik kelebihan dan kekurangan. Kampas rem asbestos akan terjadi blong atau tidak bekerja pada suhu pengereman di atas $200^{\circ} \mathrm{C}$ yang dapat menyebabkan kecelakaan. Ini disebabkan karena kandungan resin yang sangat tinggi. Sedangkan untuk kampas rem yang terbuat dari non asbestos lebih tahan panas dan terjadi rem blong pada saat suhu pengereman di atas $350^{\circ} \mathrm{C}$. Hal ini karena serat selulosa dan serat lainnya dapat meredam panas lebih baik dibandingkan serat asbes [1].

Beban pengereman berhubungan dengan tekanan yang terjadi pada kampas cakram dengan piringan cakram, semakin besar beban pengereman, maka tekananya akan semakin besar. Sedangkan berat pengendara berpengaruh terhadap besar gaya yang dibutuhkan untuk menghentikan laju kendaraan. Semakin besar berat pengendara, maka gaya yang dibutuhkan untuk menghentikan kendaraan akan semakin besar pula. Jenis produk yang berbeda akan menghasilkan nilai keausan dan waktu pengereman yang berbeda pula. Sebab, kualitas dari masing-masing jenis kampas cakram berbeda tergantung dari formula yang diberikan oleh masing-masing produsen.

Oleh karena itu, diharapkan dari penelitian ini masyarakat mengetahui penyebab terjadinya berbagai keluhan dari jenis kampas cakram dan dampaknya terhadap kesehatan dan lingkungan sehingga masyarakat menjadi lebih cerdas dalam memilih jenis kampas cakram yang terbaik untuk digunakan di motor mereka. Selain itu, 
kita akan mendapatkan gambaran tentang pengaruh besar beban pengereman dan berat pengendara terhadap keausan dan waktu pengereman pada produk kampas cakram yang berbeda.

\section{TUJUAN PENELITIAN}

Tujuan dari penelitian ini adalah untuk mengetahui pengaruh beban pengereman dan berat pengendara terhadap nilai keausan dan waktu pengereman kampas cakram asbestos dan non asbestos agar masyarakat secara umum dapat mengetahui perbedaan dari masing-masing produk.

\section{MANFAAT PENELITIAN}

Manfaat yang diharapkan dari penelitian ini adalah untuk menambah wawasan pengetahuan tentang sistem pengereman, dapat menjadi acuan bagi penelitian-penelitian berikutnya terutama dalam penelitian kampas cakram, masyarakat dapat lebih cerdas dalam memilih kampas cakram yang aman bagi kesehatan dan ramah lingkungan.

\section{LANDASAN TEORI}

Kampas cakram sepeda motor ada yang terbuat dari bahan asbes dan ada yang terbuat dari bahan non asbes. Keduanya memiliki perbedaan dalam ketahanan terhadap suhu yang terjadi di mana kampas rem masih mampu bekerja. Kampas rem asbestos akan terjadi blong atau tidak bekerja pada suhu pengereman di atas $200^{\circ} \mathrm{C}$ yang dapat menyebabkan kecelakaan. Ini disebabkan karena kandungan resin yang sangat tinggi. Sedangkan untuk kampas rem yang terbuat dari non asbestos lebih tahan panas dan terjadi rem blong pada saat suhu pengereman di atas $350^{\circ} \mathrm{C}$. Hal ini karena serat selulosa dan serat lainnya dapat meredam panas lebih baik dibandingkan serat asbes [1].

Asbes adalah serat mineral yang berasal dari batuan yang berasal dari dalam bumi yang diperoleh dari proses penambangan bawah tanah. Sebenarnya asbes termasuk dalam kategori bahan yang sangat berbahaya, karena asbes terdiri dari serat-serat yang berukuran sangat kecil, kirakira lebih tipis dari1/700 rambut kita. Seratserat ini menguap di udara dan tidak larut dalam air, jika terhirup oleh paru-paru akan menetap di sana dan dapat menyebabkan berbagai macam penyakit [2].

Pada setiap kendaraan bermotor kemampuan sistem pengereman menjadi suatu yang sangat penting karena dapat mempengaruhi keselamatan kendaraan tersebut. Semakin tinggi kemampuan kendaraan tersebut untuk melaju maka semakin tinggi pula tuntutan kemampuan sistem rem yang lebih handal dan optimal untuk menghentikan atau memperlambat laju kendaraan tersebut. Sistem rem yang baik adalah sistem rem yang jika dilakukan pengereman baik dalam kondisi apapun pengemudi tetap dapat mengendalikan arah dan laju kendaraannya [3].

Jenis Kampas Rem Menurut Klasifikasi International:

a. OEM (Original Equipment Manufactured) OEM adalah jenis kampas rem yang sudah terpasang pada saat membeli motor baru, dimana untuk produsen Honda, Suzuki, dan Kawasaki dikeluarkan oleh pabrikan rem Nissin, sedangkan untuk Yamaha dikeluarkan oleh Akebono.

b. OES (Original Equipment Sparepart)

OES adalah jenis kampas rem yang digunakan sebagai pengganti kampas rem OEM dimana kampas rem ini dibuat oleh pabrikan OEM sehingga mempunyai kode formula yang sama, proses yang sama, kualitas yang sama dan bahan yang sama dengan kampas rem OEM.

c. After Market

Jenis ini adalah kampas rem yang beredar di pasaran, dengan kualitas yang beragam. Ada yang mempunyai kualitas lebih rendah dari OEM, dan ada yang lebih tinggi kualitasnya dari OEM.

d. Genuine

Pada dasarnya kampas rem ini masuk dalam kategori jenis After Market. Istilah Genuine hanya untuk membedakan antara asli dan palsu tidaknya produk tersebut [4].

\section{METODE PENELITIAN}

Pada penelitian ini digunakan 3 merek kampas cakram yaitu kampas cakram AHM, Unibear dan Federal. Kampas cakram AHM termasuk jenis non asbestos, kampas cakram Uniber termasuk jenis kampas cakram non asbestos dan federal termasuk kampas cakram jenis asbestos.

Untuk masing-masing sampel kampas cakram yang diuji, baik sisi kampas cakram yang kiri maupun yang kanan, diberi titik pengukuran sebanyak 10 titik untuk mendapatkan hasil yang lebih akurat. Penentuan titik pengukuran tersebut dapat dilihat pada gambar 1 .

Penelitian dilakukan secara langsung di jalan utama universitas mataram, di bagian 
utara fakultas teknik pada pukul 08.00-12.00 dengan menggunakan sepeda motor Honda Supra X 125 cc. Beban pengereman divariasikan dengan $2 \mathrm{~kg}$, $3 \mathrm{~kg}$ dan $4 \mathrm{~kg}$, dan dengan total berat pengendara adalah $54 \mathrm{~kg}$ dan $111 \mathrm{~kg}$. Metode pembebanan pada kendaraan dapat dilihat pada gambar 2 . Kondisi pengereman divariasikan pada kondisi kering dan kondisi basah. Kampas cakram yang digunakan pada kondisi kering dan kondisi basah berbeda. Sehingga kampas cakram yang digunakan untuk masing-masing merek yang berbeda adalah 2 sampel. Satu untuk kondisi kering dan satu untuk kondisi basah. Mekanisme pengairan kontinyu untuk kondisi basah dapat dilihat pada gambar 3 .

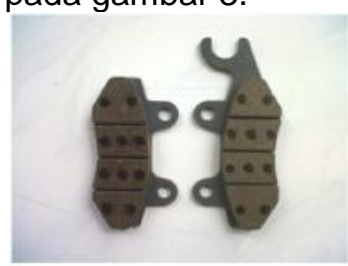

(a)

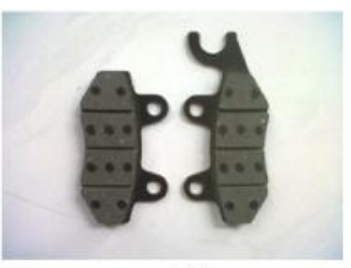

(b)

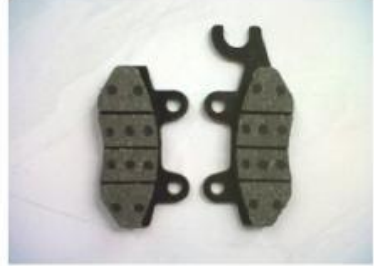

(c)

Gambar 1. Titik pengukuran (a) Kampas cakram A (b) Kampas cakram B (c) Kampas cakram C

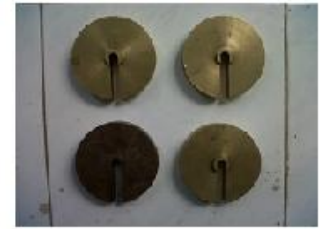

(a)

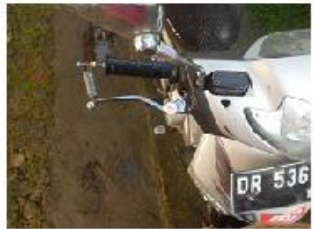

(c)

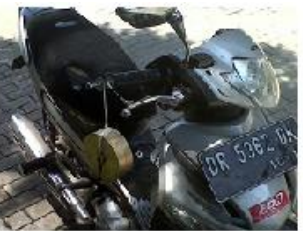

(b)

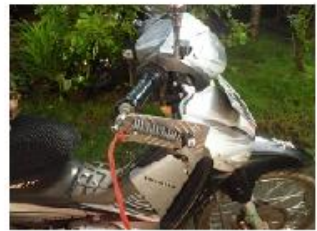

(d)
Gambar 2. Proses pembebanan (a) Besi beban langsung (b) Penentuan pembebanan

(c) Posisi pegas rem dalam keadaan mengerem (d) Posisi pegas rem diganjel dalam keadaan belum mengerem

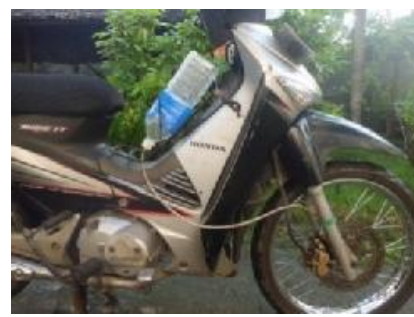

Gambar 3. Mekanisme pengairan secara kontinyu

Pengukuran dilakukan di lab. Metrologi Fakultas Teknik Universitas Mataram menggunakan alat ukur mikrometer dengan ketelitian 0,001 mm. Beban yang digunakan sebagai variasi penelitian menggunakan besi dan yang digunakan pada peneltian secara langsung di kendaraan motor menggunakan pir dengan $\mathrm{k}=65,5$ $\mathrm{N} / \mathrm{mm}$. Untuk mengganjal handel terhadap stang agar tidak mengerem pada saat kendaraan akan dijalankan menggunakan alumunium yang telah didesain. Tahapan penelitian berupa diagram alir penelitian dapat dilihat pada gambar 4 . 


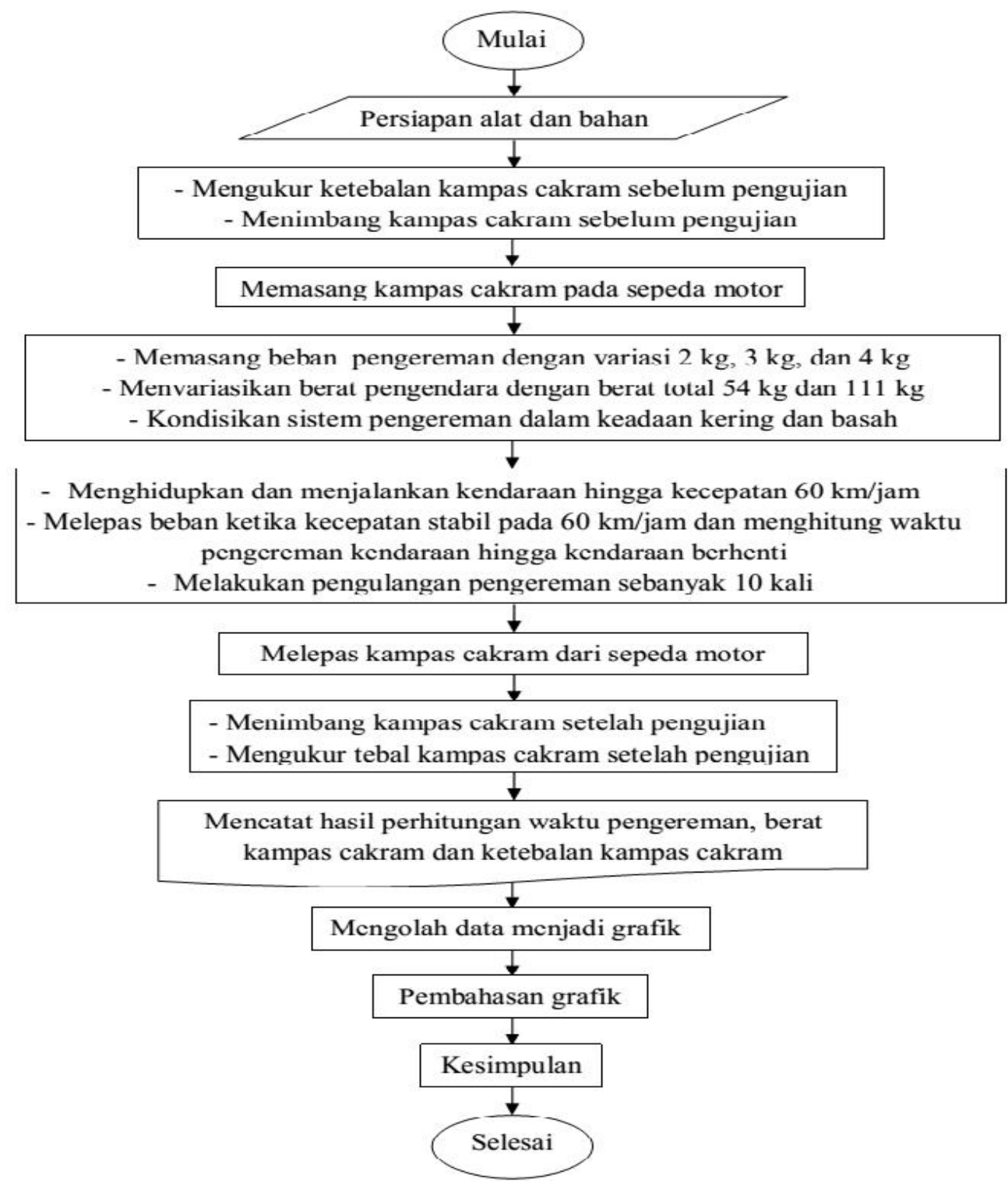

Gambar 4. Diagram alir penelitian

\section{HASIL DAN PEMBAHASAN}

Dari hasil penelitian yang telah dilakukan,diperoleh data yang menunjukkan pengaruh variasi beban pengereman dan berat pengendara terhadap nilai keausan dan waktu pengereman dari masing-masing kampas cakram dengan merek dan jenis yang berbeda. Data-data hasil penelitian tersebut dikumpulkan dan dimasukkan ke dalam tabel yang berbeda-beda, sesuai variasi perlakuan yang telah ditentukan.
Data mentah yang didapat berupa ketebalan kampas cakram sebelum pengereman dan setelah pengereman. Selain itu, didapatkan juga waktu pengereman semenjak melepas beban pengereman hingga kendaraan berhenti total. Data-data tersebut diolah ke dalam tabel dan diubah menjadi grafik seperti di bawah ini.

1. Pengaruh Beban Pengereman dan Berat Pengendara Terhadap Laju Keausan dan Waktu Pengereman Kampas Cakram Pada Kondisi Kering 


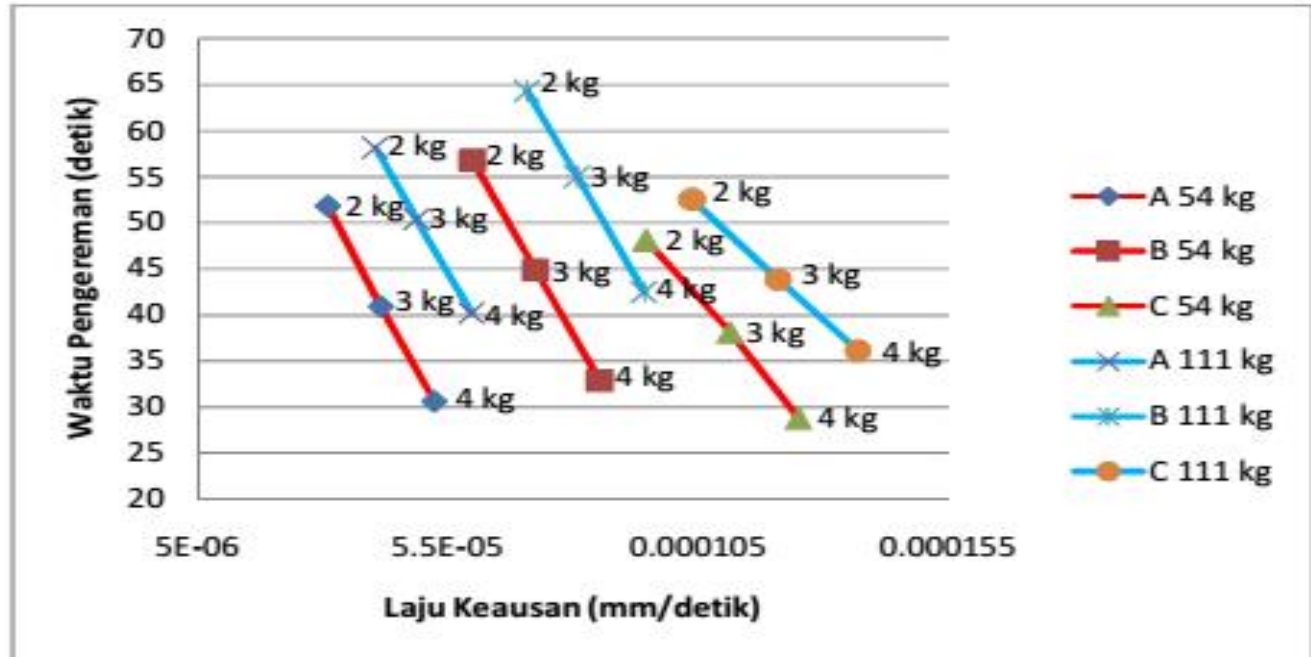

Gambar 5. Grafik Perbandingan Laju Keausan dan Waktu Pengereman Kampas Cakram Pada Kondisi Kering

Pada gambar grafik di atas, terlihat perbedaan yang cukup signifikan, di mana keausan terbesar terjadi pada kampas cakram $\mathrm{C}$ dengan beban pengereman $4 \mathrm{~kg}$ dan berat pengendara $111 \mathrm{~kg}$ dan menghasilkan laju keausan sebesar $1,37 \times 10^{-4}$ $\mathrm{mm} /$ detik dengan total waktu pengereman sebesar 36,12 detik. Hal ini disebabkan karena kampas cakram C yang berbahan asbes memiliki kekurangan dalam hal keausan pada kondisi kering, namun waktu yang dihasilkan lebih sedikit dibandingkan kampas cakram yang lain. Koefisien gesek asbestos pada kondisi kering lebih baik dari non asbestos tetapi kurang tahan terhadap tekanan [5].

Keausan terkecil terjadi pada kampas cakram A dengan beban pengereman $2 \mathrm{~kg}$ dan menghasilkan laju keausan sebesar $4,043 \times 10^{-5} \mathrm{~mm} /$ detik dengan total waktu pengereman sebesar 58,13 detik. Hal ini disebabkan karena kekuatan kampas cakram A yang berbahan non asbes lebih baik dalam ketahanan aus dari pada kampas cakram B dan $C$ dalam kondisi kering. Walaupun kampas cakram A dan B sama-sama berbahan non asbestos, namun formula kampas cakram A lebih baik dari pada kampas cakram B. Kampas cakram A termasuk kategori OES (Original Equipment Sparepart) yakni kampas cakram yang dibuat oleh pabrik astra dan kualitasnya sama dengan kampas cakram OEM (Original Equipment Manufacture) yang terpasang saat membeli motor baru [4].

Waktu yang paling besar yang dibutuhkan untuk menghentikan laju kendaraan terjadi pada kampas cakram B dengan beban pengereman $2 \mathrm{~kg}$ dan berat pengendara $111 \mathrm{~kg}$ dengan total waktu pengereman sebesar 64,26 detik. Hal ini disebabkan karena kampas cakram A memiliki daya cengkram yang lebih baik dibandingkan kampas cakram B dan kampas cakram $\mathrm{C}$ yang berbahan asbes lebih unggul dalam hal daya cengkram dibandingkan kampas cakram B dalam kondisi kering. Hal tersebut didukung juga oleh beban pengereman yang paling kecil pada penelitian ini, sehingga menyebabkan gesekan antara kampas cakram dengan piringan adalah paling kecil.

Waktu yang paling kecil yang dibutuhkan untuk menghentikan laju kendaraan terjadi pada kampas cakram C dengan beban pengereman $4 \mathrm{~kg}$ dan berat pengendara $111 \mathrm{~kg}$ dengan total waktu pengereman sebesar 36,12 detik. Hal ini disebabkan karena kampas cakram C yang berbahan asbes lebih unggul dalam daya cengkram dibandingkan kampas cakram A dan $B$ dalam kondisi kering. Beban pengereman berkaitan erat dengan waktu pengereman. Semakin besar beban pengereman dengan kecepatan yang sama, maka akan menghasilkan waktu pengereman yang semakin kecil karena beban yang semakin besar akan menghasilkan gaya gesek yang semakin besar [6].

\section{Pengaruh Beban Pengereman dan Berat Pengendara Terhadap Laju Keausan dan Waktu Pengereman Kampas Cakram Pada Kondisi Basah}




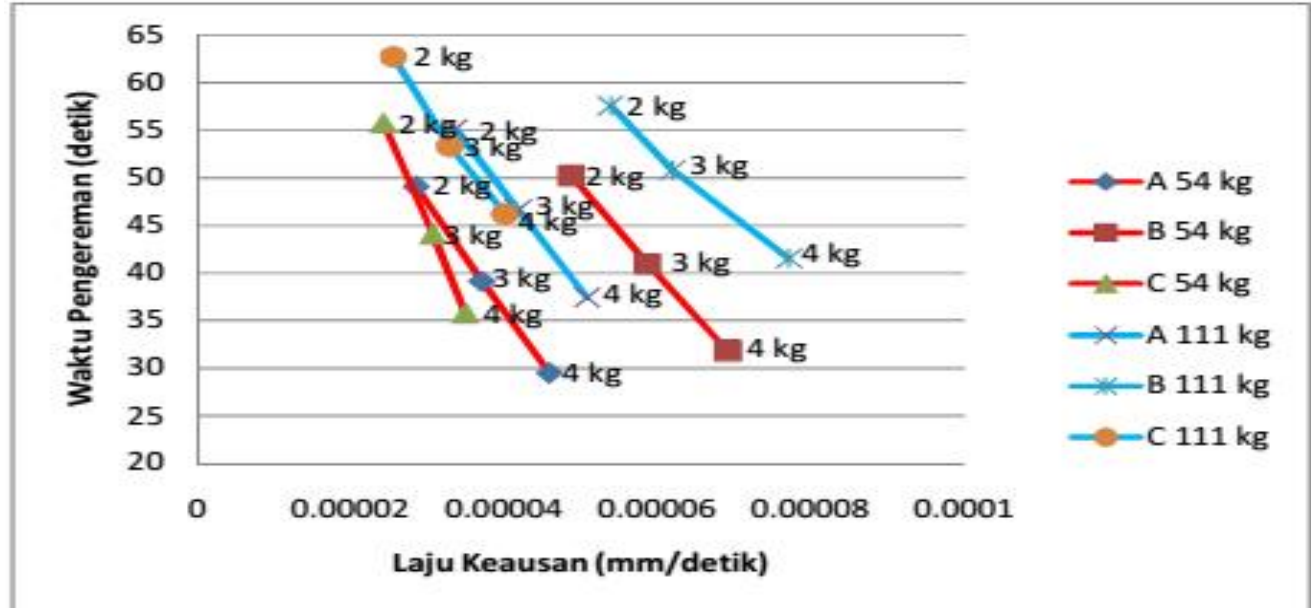

Gambar 6. Grafik Perbandingan Laju Keausan dan Waktu Pengereman Kampas Cakram Pada Kondisi Basah

Pada gambar grafik di atas, terlihat perbedaan yang cukup signifikan, di mana keausan terbesar terjadi pada kampas cakram $B$ dengan beban pengereman $4 \mathrm{~kg}$ dan berat pengendara $111 \mathrm{~kg}$ dan menghasilkan laju keausan sebesar $7,716 \times 10$ $5 \mathrm{~mm} /$ detik dan dengan total waktu pengereman sebesar 41,47 detik. Hal ini disebabkan karena material kampas cakram A yang non asbestos memiliki ketahanan aus yang lebih tinggi dibandingkan kampas cakram B yang juga non asbestos. Selain itu, kampas cakram A juga memiliki daya cengkram yang lebih baik dibandingkan kampas cakram B, sehingga waktu yang dihasilkan A lebih sedikit dibandingkan kampas cakram B. Sedangkan kampas cakram C yang berbahan asbes cenderung memiliki efek licin pada kondisi basah, sehingga tingkat keausannya lebih rendah. Besar beban pengereman $4 \mathrm{~kg}$ yang merupakan beban maksimum yang digunakan pada penelitian ini menyebabkan kampas cakram mengalami tingkat keausan maksimum. Karena semakin besar beban pengereman, maka gesekan yang terjadi antara kampas cakram dengan piringan akan semakin besar, sehingga tingkat keausannya akan semakin bertambah [6].

Keausan terkecil terjadi pada kampas cakram $\mathrm{C}$ dengan beban pengereman $2 \mathrm{~kg}$ dan berat pengendara $54 \mathrm{~kg}$ dan menghasilkan laju keausan sebesar 2,422×10 ${ }^{5} \mathrm{~mm} /$ detik dengan total waktu pengereman sebesar 55,75 detik. Hal ini disebabkan karena kampas cakram $\mathrm{C}$ yang berbahan asbes cenderung memiliki efek licin pada kondisi basah, sehingga tingkat keausannya lebih rendah dan waktu yang dibutuhkan untuk menghentikan laju kendaraan semakin banyak. Kampas rem asbestos hanya memiliki satu jenis fiber yaitu asbes yang merupakan material yang menimbulkan karsinogenik, sehingga kampas rem ini memiliki kelemahan pada saat kondisi basah yang mengakibatkan efek licin waktu pengereman [7].

Waktu yang paling besar yang dibutuhkan untuk menghentikan laju kendaraan terjadi pada kampas cakram C dengan berat pengendara $111 \mathrm{~kg}$, beban pengereman $2 \mathrm{~kg}$ dan menghasilkan waktu 62,71 detik. Hal ini disebabkan karena kampas cakram $\mathrm{C}$ yang berbahan asbes cenderung memiliki efek licin pada kondisi basah, sehingga daya cengkramnya menurun dan mengakibatkan waktu pengereman yang semakin banyak. Hal tersebut didukung juga oleh beban pengereman yang paling kecil pada penelitian ini, sehingga menyebabkan gesekan antara kampas cakram dengan piringan adalah paling kecil. Selain itu, berat pengendara yang bertambah dengan besar gaya pengereman tetap, menyebabkan waktu pengereman semakin bertambah, karena semakin besar berat pengendara, maka dibutuhkan gaya pengereman yang semakin besar pula untuk dapat menghentikan laju kendaraan.

Waktu yang paling kecil yang dibutuhkan untuk menghentikan laju kendaraan terjadi pada kampas cakram A dengan beban pengereman $4 \mathrm{~kg}$ dan berat pengendara $54 \mathrm{~kg}$ dengan total waktu pengereman sebesar 37,4 detik. Hal ini disebabkan kampas cakram $\mathrm{A}$ yang berbahan non asbes memiliki daya cengkram yang lebih tinggi dibandingkan kampas cakram B dan C. Selain itu, daya cengkram kampas cakram berbahan non asbes akan bertambah pada kondisi basah. Hal tersebut sesuai dengan data hasil penelitian. Sehubungan dengan 
beban pengereman yang maksimum pada beban $4 \mathrm{~kg}$ menyebabkan terjadinya usaha maksimum yang dilakukan kampas cakram untuk menghentikan laju kendaraan, sehingga waktu pengereman semakin kecil.

\section{KESIMPULAN}

Berdasarkan data hasil penelitian yang telah dilakukan, maka ada beberapa hal yang dapat di sebagai kesimpulan sebagai berikut:

1. Dalam kondisi kering, keausan terbesar terjadi pada kampas cakram $\mathrm{C}$ dengan beban pengereman $4 \mathrm{~kg}$ dan berat pengendara $111 \mathrm{~kg}$ dan menghasilkan keausan sebesar $1,37 \times 10^{-4} \mathrm{~mm} /$ detik dan keausan terkecil terjadi pada kampas cakram $A$ dengan beban pengereman $2 \mathrm{~kg}$ dan berat pengendara $54 \mathrm{~kg}$ dan menghasilkan keausan sebesar $3,088 \times 10^{-5}$ $\mathrm{mm} /$ detik.

2. Dalam kondisi basah, keausan terbesar terjadi pada kampas cakram B dengan beban pengereman $4 \mathrm{~kg}$ dan berat pengendara $111 \mathrm{~kg}$ dan menghasilkan keausan sebesar $7,716 \times 10^{-5} \mathrm{~mm} /$ detik dan keausan terkecil terjadi pada kampas cakram $\mathrm{C}$ dengan beban pengereman $2 \mathrm{~kg}$ dan berat pengendara $54 \mathrm{~kg}$ dan menghasilkan keausan sebesar $2,422 \times 10^{-5}$ $\mathrm{mm} /$ detik.

3. Waktu yang paling banyak yang dibutuhkan oleh kampas cakram untuk menghentikan laju kendaraan pada kondisi kering terjadi pada kampas cakram B dengan beban pengereman $2 \mathrm{~kg}$, berat pengendara $111 \mathrm{~kg}$ dengan waktu 64,26 detik, sedangkan waktu yang paling sedikit yang dibutuhkan oleh kampas cakram untuk menghentikan laju kendaraan pada kondisi kering terjadi pada kampas cakram $\mathrm{C}$ dengan beban pengereman $4 \mathrm{~kg}$, berat pengendara $54 \mathrm{~kg}$ dengan waktu 28,79 detik.

4. Waktu yang paling banyak yang dibutuhkan oleh kampas cakram untuk menghentikan laju kendaraan pada kondisi basah terjadi pada kampas cakram C dengan beban pengereman $2 \mathrm{~kg}$, berat pengendara $111 \mathrm{~kg}$ dengan waktu 62,71 detik, sedangkan waktu yang paling sedikit yang dibutuhkan oleh kampas cakram untuk menghentikan laju kendaraan terjadi pada kampas cakram A dengan beban pengereman $4 \mathrm{~kg}$, berat pengendara $54 \mathrm{~kg}$ dengan waktu 29,46 detik.

5. Seiring bertambahnya beban pengereman, selalu diikuti dengan peningkatan laju keausan dan penurunan waktu pengereman pada semua jenis kampas cakram.
6. Seiring bertambahnya berat pengendara, selalu diikuti dengan peningkatan laju keausan dan waktu pengereman pada semua jenis kampas cakram.

7. Kampas cakram asbestos mengalami peningkatan waktu pengereman pada kondisi basah dibandingkan dengan kondisi kering.

8. Kampas cakram non asbestos mengalami penurunan waktu pengereman pada kondisi basah dibandingkan dengan kondisi kering.

\section{SARAN}

Bagi peneliti berikutnya agar selalu berhati-hati dalam melakukan pengujian dengan memperhatikan kesehatan dan keselamatan. Dan untuk mendapatkan hasil yang maksimal dalam penelitian, diharapkan ketelitian yang lebih baik dari peneliti dalam mengambil data.

Kita harus memilih kampas cakram yang tepat untuk digunakan di daerah yang akan kita lalui setiap hari. Kita harus menyesuaikan kondisi iklim dan kondisi lingkungan yang ada pada daerah kita. Ada daerah yang basah dan ada yang kering. Karena kondisi tersebut mempengaruhi kinerja dari jenis kampas cakram yang kita gunakan.

Pada kondisi kering, jika kita menginginkan keausan yang lebih rendah, maka kita lebih baik menggunakan kampas cakram non asbestos, namun jika kita menginginkan waktu pengereman yang lebih singkat maka lebih baik kita menggunakan kampas cakram asbestos. Sedangkan pada kondisi basah, jika kita menginginkan keausan yang lebih rendah, maka kita lebih baik menggunakan kampas cakram asbestos, namun jika kita menginginkan waktu pengereman yang lebih singkat maka lebih baik kita menggunakan kampas cakram non asbestos.

\section{DAFTAR PUSTAKA}

[1] Sukamto, Bardi A.J., 2013, Analisis Perpindahan Panas Kampas Rem Pada Sepeda Motor, Teknik Mesin Universitas Janabadra, Yogyakarta.

[2] Alviontina, C.O., dan Trisna, I.T.A., 2011, Teknologi Bahan Konstruksi, Universitas Sains Al-Qur'an, Jawa Tengah.

[3] Welianto, A., 2010, Pengaruh Keausan Brake Pad Terhadap Waktu Pengereman Pada Pengujian Stationer, Jurusan Teknik Mesin Universitas Kristen Petra, Surabaya. 
[4] Sukamto, 2012, Analisis Keausan Kampas Rem Pada Sepeda Motor, Teknik Mesin Universitas Janabadra, Yogyakarta.

[5] Isbullah, Haryadi,W., dan Dwi G., 2013, Prediksi Kegagalan Sistem Rem Cakram Pada Sepeda Motor Honda Supra X 125, Universitas Diponegoro, Semarang.

[6] Febrianto, D., 2012, Analisa Pengaruh Kecepatan dan Beban Pengereman
Terhadap Keausan Kampas Rem Pada Sepeda Motor Honda Supra X 125 cc, Teknik Mesin Universitas Mataram, Mataram.

[7] Multazam, A., Zainuri, A., dan Sujita, 2012, Analisa Pengaruh Variasi Merek Kampas Rem Tromol dan Kecepatan Sepeda Motor Honda Supra X 125 Terhadap Keausan Kampas Rem, Universitas Mataram, Mataram. 